Odjel za polimere

DOI: 10.15255/KUI.2017.012a

Pododbor za nazivlje (terminologiju) polimera

KUI-11/2018

Nomenklatura i terminologija iz područja

Nomenklaturni prikaz

polimera i polimernih materijala

Prispjelo 27. ožujka 2017.

Prihvaćeno 30. siječnja 2018.

\title{
Imenovanje jednonitnih homopolimera i kopolimera na osnovi podrijetla (I. dio) ${ }^{* * *}$
}

\section{Preporuke IUPAC 2016. \\ Preporuke HDKI i HKD 2018.}

Pripravila radna skupina u sastavu:

Richard G. Jones*, Tatsuki Kitayama*, Karl-Heinz Helwich, Michael Hess, Aubrey D. Jenkins, Jaroslav Kahovec, Pavel Kratochvil, Itaru Mita', Werner Mormann, Christopher K. Ober, Stanistaw Penczek, Robert F. T. Stepto ${ }^{\dagger}$, Kevin Thurlow, Jiří Vohlídal, Edward S. Wilks

Prevela:

Vida Jarm*

Rudolfa Bićanića, 10000 Zagreb

uz savjete i komentare

Marice Ivanković, Jelene Macan i Zorice Veksli

\section{Sažetak}

Prethodne IUPAC-ove preporuke imenovanja (nomenklature) jednonitnih polimera na osnovi podrijetla (NOP) odnosile su se uglavnom na kopolimere, nelinearne polimere, združene polimere i generičke polimere. Pravila navedena u ovim preporukama omogućuju jasnije i preciznije imenovanje polimera na osnovi podrijetla, kako homopolimera tako i kopolimera. Prikazani sveobuhvatni sustav imenovanja polimera na osnovi podrijetla prihvatljiva je alternativa sustavu imenovanja polimera na osnovi strukture. Zbog raširene i česte uporabe dodatno su opisane i preporuke za uporabu uvriježenih imena polimera.

\section{Ključne riječi}

Prividni monomer, kopolimer, krajnje skupine, homopolimer, IUPAC, IUPAC-ovo imenovanje, monomer, imenovanje (nomenklatura), polimeri, imenovanje polimera, imenovanje polimera na osnovi podrijetla, uvriježena imena

\section{Sadržaj}

NOP-0 Uvod 135

NOP-1 Glosar 136

NOP-2 Imena homopolimera na osnovi podrijetla ..... 139

NOP-2.1 Imena monomera 139

NOP-2.1.1 Prividni monomeri 140

NOP-2.2 Imena na osnovi podrijetla za homopolimere dobivene lančanom polimerizacijom, polimerizacijom otvaranjem prstena ili poliadicijom 140 NOP-2.3 Imena na osnovi podrijetla za polimere dobivene polikondenzacijom

Literatura

Summary 144

\footnotetext{
*Dr. sc. Vida Jarm, vida.jarm@inet.hr

Recenzenti: Davor Kovačević, Marko Rogošić, Ivan Šmit, Lidija Varga-Defterdarović

** Autori za korespondenciju: Richard G. Jones, Functional Materials Group, School of Physical Sciences, University of Kent, Canterbury CT2 7NH, UK, e-pošta: kapitimana@gmail.com; i Tatsuki Kitayama, Department of Chemistry, Graduate School of Engineering, Osaka University, Toyonaka, Osaka 560-8531, Japan, e-pošta: kitayama@chem. es.osaka-u.ac.jp.

+ Preminuli
}

\section{NOP-O UVOD}

Postoje dva glavna načina sustavnoga imenovanja polimera i to "na osnovi podrijetla" (pokrata NOP; engl. source based, $\boldsymbol{S B}$ ) i "na osnovi strukture". Ime polimera dobiveno na osnovi podrijetla ne daje podatak o strukturi polimera. Da bi se iz imena na osnovi podrijetla predočila struktura polimera, potrebno je poznavati kemijski tijek postupka polimerizacije. Imenovanje na osnovi strukture u većini slučajeva je mnogo složenije, ali se iz takvoga imena struktura polimera može predočiti i bez poznavanja kemijskoga tijeka njegova dobivanja.

Opće načelo prema kojemu bi sustavno kemijsko imenovanje trebalo predočavati stvarne strukture imenovanih spojeva, u slučaju organskih polimera, postignuto je takvim imenovanjem na osnovi strukture da se pri imenovanju konstitucijskih jedinica polimera primijene stroga pravila IUPAC-ova organsko-kemijskog imenovanja. Tijekom

\footnotetext{
*** Izvornik: Richard G. Jones, Tatsuki Kitayama, Karl-Heinz Helwich, Michael Hess, Aubrey D. Jenkins, Jaroslav Kahovec, Pavel Kratochvíl, Itaru Mita, Werner Mormann, Christopher K. Ober, Stanisław Penczek, Robert F. T. Stepto, Kevin Thurlow, Jiř Vohlídal, Edward S. Wilks, Source-based nomenclature for single-strand homopolymers and copolymers (IUPAC Recommendations 2016), Pure Appl. Chem. 88 (10-11) (2016) 10731100, doi: https://doi.org/10.1515/pac-2015-0702.
} 
predsjedavanja prijašnjega Povjerenstva za imenovanje makromolekula (Commission on Macromolecular Nomenclature) i sadašnjega Odjela za kemijsko imenovanje i prikazivanje strukture (Chemical Nomenclature and Structure Representation Division) IUPAC je objavio četiri dokumen$\mathrm{ta}^{1-4} \mathrm{~s}$ pravilima o imenovanju na osnovi strukture prema kojima se može imenovati većina organskih polimera. Prema tim bi se pravilima npr. polimer sastavljen od ponavljanih konstitucijskih jedinica formule $-\mathrm{CH}\left(\mathrm{C}_{6} \mathrm{H}_{5}\right) \mathrm{CH}_{2}-$, bez obzira kojim postupkom je dobiven, trebao imenovati kao poli(1-feniletilen) ili alternativno poli(1-feniletan-1,2-diil). Međutim, unatoč točnosti koju pruža sustav imenovanja na osnovi strukture, mnogi znanstvenici u industriji i na sveučilištu godinama primjenjuju sustav imenovanja polimera na osnovi podrijetla smatrajući ga prikladnijim, jednostavnijim i lakše shvatljivim (vidi Dodatak NOP-7). Prema sustavu imenovanja na osnovi podrijetla polimer navedene strukture dobiven od monomera stirena (podrijetlo) imenuje se polistiren. Posljedica neprestane uporabe sustava imenovanja polimera na osnovi podrijetla je njegovo prihvaćanje od strane IUPAC-ova Odjela za polimere i Odjela za kemijsko imenovanje i prikazivanje strukture kao službenoga alternativnog imenovanja polimera. lako je prijašnje Povjerenstvo objavilo dokumente s pravilima imenovanja na osnovi podrijetla za linearne kopolimere, ${ }^{5}$ nelinearne polimere i združene polimere ${ }^{6}$ te generičke polimere, ${ }^{7}$ dokument koji opisuje pojedinosti imenovanja na osnovi podrijetla za jednonitne (linearne) homopolimere do danas ne postoji.

Ovaj dokument obrađuje pravila imenovanja jednonitnih polimera na osnovi podrijetla, a kako se u tom sustavu rabe i uvriježena imena monomera koja više nisu zadržana u IUPAC-ovu imenovanju, dane su i upute za uporabu uvriježenih imena. Kako bi pravila za sve jednonitne polimere bila sadržana u jednome dokumentu, uključene su i obnovljene i dopunjene ranije objavljene preporuke za imenovanje kopolimera na osnovi podrijetla. ${ }^{5}$

lako je sadržaj ovoga dokumenta temeljitiji od ranije objavljenih IUPAC-ovih preporuka za nelinearne polimerne strukture (granate, umrežene itd.) i združene polimere, ${ }^{6}$ one nisu uključene.

Nisu uključene niti preporuke za generičko imenovanje polimera na osnovi podrijetla ${ }^{7}$ koje će biti posebno obrađeno. Preporuke u navedenim dokumentima ${ }^{6,7}$ mogu se primjenjivati jedino ako su obnovljene i dopunjene u skladu s preporukama navedenim u ovome dokumentu i u preporukama za organsku kemiju. ${ }^{8}$

Nazivlje (terminologija) navedeno u ovome dokumentu uglavnom je preuzeto iz IUPAC-ove "Blue Book", "Nomenclature of Organic Chemistry". ${ }^{8}$ Nazivi i njihovo značenje su sljedeći:

preferentno IUPAC-ovo ime (preferred IUPAC name, PIN) Ime koje ima prednost pred dva ili više imena koja su nastala prema IUPAC-ovim preporukama, ali i pred brojnim skovanim i godinama rabljenim istoznačnicama.

\section{opće IUPAC-ovo imenovanje}

(general IUPAC nomenclature)

Načela, pravila i dogovori za tvorbu IUPAC-ovih imena koja se razlikuju od preferentnih IUPAC-ovih imena.

\section{uvriježeno ime (traditional name)}

Ime u općoj uporabi u jednome ili više područja kemijske struke.

\section{zadržano ime (retained name)}

Uvriježeno ime ili ime u općoj uporabi bilo kao preferentno IUPAC-ovo ime bilo kao alternativno ime nastalo općim IUPAC-ovim imenovanjem.

Napomene prevoditelja: U definicijama IUPAC-ovih preporuka kosim tiskom navedeni su nazivi koji su u istom dokumentu zasebno obrađeni. U slučaju istoznačnica svakoj je dodana oznaka normativnog statusa (preporučeni naziv $^{p}$, dopušteni naziv ${ }^{d}$, nepreporučeni naziv $\left.{ }^{n}\right)$. U ove preporuke uvršteni su Dodatak 1 i Dodatak 2 u kojima su radi lakšega snalaženja navedena dva abecedna kazala naziva i to englesko-hrvatsko i hrvatsko-englesko.

\section{NOP-1 GLOSAR}

Definicije nekih naziva u ovome dijelu dokumenta sažeti su oblik prvotnih definicija iz lit. ${ }^{9,10}$ To je načinjeno radi kratkoće i neopterećivanja čitatelja literaturnim navodima, a na primjerima je i označeno.

\section{NOP-1.1 prividni monomer (apparent monomer)}

Monomer koji prema imenu polimera izgleda kao da je bio upotrijebljen u njegovoj sintezi, a zapravo je polimer dobiven iz druge polazne tvari. Vidi također odjeljak NOP-2.1.1.

Napomena: Naziv zamjenjuje dva ranije rabljena naziva "hipotetički monomer" (engl. hypothetical monomer) i "implicitni monomer" 5,9,10 (engl. implicit monomer) koji se smatraju zastarjelima.

\section{NOP-1.2 blok (block)}

Dio makromolekule sastavljen od više konstitucijskih jedinica, a sadržava barem jednu konstitucijsku ili konfiguracijsku značajku koja nije prisutna u susjednim dijelovima..$^{9,10}$ Napomena: Gdjegod je primjereno definicije vezane uz makromolekulu mogu se primijeniti i na blok.

\section{NOP-1.3 blok-polimer (block polymer)}

Polimer sastavljen od blok-makromolekula. ${ }^{9,10}$

\section{NOP-1.4 lanac (chain)}

Cijela makromolekula, oligomerna molekula ili blok ili njihov dio građeni od linearnih ili granatih slijedova konstitucijskih jedinica između dviju graničnih konstitucijskih jedinica od kojih svaka može biti krajnja skupina, granište ili neki drugi karakteristični element makromolekule..$^{9,10}$

Napomena 1: Osim za linearne jednonitne makromolekule definicija lanca može biti i drugačije dogovorena.

Napomena 2: lako ciklička makromolekula nema krajnjih skupina, može se smatrati lancem. 
Napomena 3: Između graničnih jedinica može biti bilo koji broj graništa.

Napomena 4: Gdjegod je primjereno, definicije koje se odnose na makromolekulu mogu se primijeniti i na lanac.

\section{NOP-1.4.1 glavni lanac (main chain)}

Linearni lanac na kojemu se svi drugi lanci, dugi ili kratki ili i jedni i drugi, mogu smatrati bočnim lancima. ${ }^{9,10}$

\section{NOP-1.4.2 bočni lanac (side chain)}

Oligomerni ili polimerni izdanak na makromolekulskome lancu. ${ }^{9,10}$

\section{NOP- 1.5 lančana polimerizacija (chain polymerization)}

Lančana reakcija ${ }^{10} \mathrm{u}$ kojoj se rast polimernoga lanca odvija isključivo reakcijom (reakcijama) između molekule monomera (molekula monomera) i aktivnog (aktivnih) mjesta na polimernomu lancu uz obnavljanje aktivnoga (aktivnih) mjesta na kraju svakog koraka rasta. ${ }^{11}$

Napomena 1: Lančana polimerizacija se sastoji od reakcija inicijacije i propagacije lanca, a može uključivati i reakcije deaktivacije ili prijenosa rasta lanca ili obje.

Napomena 2: Propagacija se u lančanoj polimerizaciji uobičajeno odvija bez nastajanja malih molekula. Međutim postoje slučajevi u kojima nastaju nusproizvodi malih molarnih masa, kao što je to slučaj pri polimerizaciji oksazolidin-2,5-diona dobivenih iz aminokiselina (uvriježenoga imena $N$-karboksianhidridi aminokiselina). U slučaju nastajanja nusproizvoda malih molarnih masa preporučuje se dodati pridjev kondenzacijska, pa naziv glasi "kondenzacijska lančana polimerizacija".

Napomena 3: Koraci rasta prikazuju se kao:

$$
\mathrm{P}_{X}+\mathrm{M} \rightarrow \mathrm{P}_{X+1}(+\mathrm{L}) x \in\{1,2, \ldots \infty\}
$$

gdje $P_{X}$ označava rastući lanac stupnja polimerizacije $x, M$ je monomer, a $L$ je nusproizvod male molarne mase nastao u slučaju kondenzacijske lančane polimerizacije.

Napomena 4: Naziv lančana polimerizacija može se ako je potrebno proširiti kako bi se pobliže opisale vrste kemijskih reakcija koje sudjeluju u stupnju rasta, npr. lančana polimerizacija otvaranjem prstena, kationska lančana polimerizacija.

Napomena 5: Iznimno, postoje polimerizacije koje se odvijaju lančanim reakcijama, a koje prema definiciji nisu lančane reakcije. Na primjer, polimerizacija

$$
\begin{aligned}
& \mathrm{HS}-\mathrm{X}-\mathrm{SH}+\mathrm{H}_{2} \mathrm{C}=\mathrm{CH}-\mathrm{Y}-\mathrm{CH}=\mathrm{CH}_{2} \rightarrow \\
& \rightarrow\left(-\mathrm{S}-\mathrm{X}-\mathrm{S}-\mathrm{CH}_{2}-\mathrm{CH}_{2}-\mathrm{Y}-\mathrm{CH}_{2}-\mathrm{CH}_{2}-\right)_{n}
\end{aligned}
$$

odvija se radikalskom lančanom reakcijom uz međumolekulski prijenos radikalskoga centra. Stupanj rasta u takvim polimerizacijama uključuje reakcije između molekula svih stupnjeva polimerizacije, pa se iste klasificiraju kao poliadicije. Ako je potrebno, podjela može biti još preciznija i takve se polimerizacije mogu opisati kao lančane reakcije poliadicije.

Napomena 6: Prilagođeno prema definiciji u lit. ${ }^{11}$

\section{NOP-1.6 konstitucijska jedinica (constitutional unit)}

Atom ili skupina atoma (zajedno s bočnim atomima ili skupinama, ukoliko postoje) koji tvore bitni dio strukture makromolekule, oligomerne molekule, bloka ili lanca..,10

\section{NOP-1.7 ponavljana konstitucijska jedinica, PKJ (constitutional repeating unit, $C R U$ )}

Najmanja konstitucijska jedinica čije ponavljanje tvori pravilnu makromolekulu, pravilnu oligomernu molekulu, pravilni blok ili pravilni lanac. ${ }^{9,10}$

\section{NOP-1.8 kopolimer (copolymer)}

Polimer izveden od više vrsta monomera ili prividnih monomera.

Napomena 1: Kopolimeri dobiveni kopolimerizacijom dvije vrste monomera ponekad se nazivaju bipolimeri, oni dobiveni od tri monomera terpolimeri, a oni dobiveni od četiri monomera kvaterpolimeri itd.

Napomena 2: Prilagođeno prema definiciji u lit. ${ }^{9,10}$

\section{NOP-1.8.1 izmjenični kopolimerp ${ }^{p}$, alternirajući

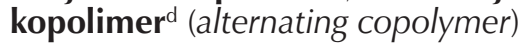

Kopolimer sastavljen od makromolekula koje su građene od dvije vrste monomernih jedinica u izmjeničnome slijedu.

Napomena 1: Izmjenični kopolimer se može smatrati homopolimerom izvedenim od prividnoga monomera.

Napomena 2: Prilagođeno prema definiciji u lit. ${ }^{9,10}$

\section{NOP-1.8.2 blok-kopolimer (block copolymer)}

Kopolimer koji je blok-polimer. ${ }^{9,10}$

Napomena: U makromolekulama koje čine blok-kopolimer susjedni se blokovi razlikuju po konstituciji, tj. susjedne blokove tvore konstitucijske jedinice izvedene od različitih vrsta monomera ili od iste vrste monomera, ali različitoga sastava ili različite slijedne raspodjele konstitucijskih jedinica.

\section{NOP-1.8.3 cijepljeni kopolimer (graft copolymer)}

Kopolimer koji je cijepljeni polimer. ${ }^{9,10}$

Napomena: U makromolekulama cijepljenoga kopolimera susjedni blokovi glavnoga lanca ili bočnih lanaca ili oba razlikuju se po konstituciji, tj. susjedne blokove tvore konstitucijske jedinice izvedene od različitih vrsta monomera ili od iste vrste monomera, ali različitoga sastava ili različite slijedne raspodjele konstitucijskih jedinica. 
NOP-1.8.4 periodični kopolimer (periodic copolymer)

Kopolimer sastavljen od makromolekula koje sadržavaju više od dvije vrste monomernih jedinica u pravilnome slijedu. ${ }^{9,10}$

\section{NOP-1.8.5 slučajni kopolimer ${ }^{p}$, nasumični kopolimer ${ }^{d}$ (random copolymer)}

Kopolimer sastavljen od makromolekula u kojima je vjerojatnost nalaženja određene monomerne jedinice na bilo kojemu mjestu u lancu neovisna o prirodi susjednih jedinica. ${ }^{9,10}$

Napomena: U slučajnom kopolimeru slijedna raspodjela monomernih jedinica zadovoljava Bernoullijevu statistiku.

\section{NOP-1.8.6 statistički kopolimer (statistical copolymer)}

Kopolimer sastavljen od makromolekula u kojima slijedna raspodjela monomernih jedinica zadovoljava poznate statističke zakone..$^{9,10}$

Napomena: Primjer statističkoga kopolimera je kopolimer sastavljen od makromolekula sa slijednom raspodjelom monomernih jedinica koji zadovoljava Markovljevu statistiku.

\section{NOP-1.9 krajnja skupina ${ }^{p}$, terminalna skupina (end group)}

Konstitucijska jedinica koja čini krajnji dio makromolekule ili oligomerne molekule. ${ }^{9,10}$

\section{NOP-1.10 cijepljeni polimer (graft polymer)}

Polimer koji čine cijepljene makromolekule, tj. makromolekule sačinjene od jedne vrste ili više vrsta blokova vezanih na glavni lanac kao bočni lanci, a ti bočni lanci sadržavaju konstitucijske ili konfiguracijske značajke različite od onih u glavnomu lancu. Vidi također cijepljeni homopolimer.

Napomena: Kombinacija definicija 1.28 (cijepljena makromolekula) i 2.23 (cijepljeni polimer) u lit. ${ }^{9}$

\section{NOP-1.11 homopolimer (homopolymer)}

Polimer dobiven od samo jedne vrste stvarnoga monomera ili prividnoga monomera.

Napomena: Prilagođeno prema definiciji u lit. ${ }^{9,10}$

\section{NOP-1.11.1 blok-homopolimer (block homopolymer)}

Homopolimer čije su makromolekule građene od blokova koji sadržavaju barem jednu konstitucijsku ili konfiguracijsku značajku koja nije prisutna u susjednim dijelovima.

\section{NOP-1.11.2 cijepljeni homopolimer} (graft homopolymer)
Homopolimer čije makromolekule sadržavaju jednu ili više vrsta blokova vezanih na glavni lanac u obliku bočnih lanaca, a ti bočni lanci sadržavaju konstitucijske ili konfiguracijske značajke različite od onih u glavnome lancu.

\section{NOP-1.12 nepravilni polimer (irregular polymer)}

Polimer koji čine nepravilne makromolekule građene ponavljanjem više od jedne vrste konstitucijskih jedinica ili makromolekule građene od konstitucijskih jedinica koje nisu povezane na isti način s obzirom na smjer vezanja.

Napomena: Kombinacija definicija 1.5 (nepravilna makromolekula) i 2.16 (nepravilni polimer) u lit. $^{9}$

\section{NOP-1.13 lokant (locant)}

Broj ili slovo koji utvrđuju položaj u strukturi. ${ }^{1}$

Napomena: Lokant se pojavljuje u imenu ili općenitomu izrazu kao što je "2-supstituirani".

\section{NOP-1.14 makromolekula (macromolecule)}

Molekula velike relativne molekulske mase građena uglavnom od višestruko ponavljanih jedinica izvedenih, stvarno ili prividno, od molekula male relativne molekulske mase. ${ }^{9,10}$

\section{NOP-1.14.1 pravilna makromolekula (regular macromolecule)}

Makromolekula građena pretežito ponavljanjem istovrsnih konstitucijskih jedinica koje su sve povezane na isti način s obzirom na smjer vezanja. ${ }^{9,10}$

\section{NOP-1.15 monomer (monomer)}

Tvar sastavljena od molekula monomera. ${ }^{9,10}$

NOP-1.16 monomerna jedinica (monomeric unit, monomer unit)

Najveća konstitucijska jedinica u strukturi makromolekule ili oligomerne molekule nastala iz jedne molekule monomera. ${ }^{9,10}$

Napomena: Najveća konstitucijska jedinica nastala iz jedne monomerne molekule, koja doprinosi strukturi makromolekule ili oligomerne molekule može se opisati kao monomer ili monomerna jedinica.

\section{NOP-1.17 molekula monomera (monomer molecule)}

Molekula koja tvori konstitucijske jedinice bitne za strukturu makromolekule.

Napomena: Ispravak definicije u lit. ${ }^{9,10}$ prema kojoj jedna molekula može polimerizirati. 


\section{NOP-1.18 molekula oligomera (oligomer molecule)}

Molekula srednje relativne molekulske mase, građena od maloga broja jedinica izvedenih, stvarno ili prividno, od molekula manje relativne molekulske mase. ${ }^{9,10}$

Napomena 1: Smatra se da molekula ima srednju molekulsku masu ako se njezina svojstva značajno mijenjaju uklanjanjem jedne ili nekoliko jedinica.

Napomena 2: Ako dio ili cijela molekula imaju srednju relativnu molekulsku masu i sadržavaju mali broj jedinica izvedenih, stvarno ili prividno, od molekula manje relativne molekulske mase, ona se može opisati kao "oligomer" ili "oligomerna molekula".

\section{NOP-1.19 poliadicija (polyadition)}

Polimerizacija u kojoj se rast polimernih lanaca odvija reakcijama adicije molekula svih stupnjeva polimerizacije. ${ }^{9,10}$

\section{NOP-1.20 polikondenzacija (polycondensation)}

Polimerizacija u kojoj se rast polimernih lanaca odvija reakcijama kondenzacije između molekula svih stupnjeva polimerizacije..$^{9,10}$

\section{NOP-1.21 polimer (polymer)}

Tvar sastavljena od makromolekula. ${ }^{9,10}$

\section{NOP-1.22 pravilni polimer (regular polymer)}

Polimer sastavljen od pravilnih makromolekula, pravilnih zvjezdastih makromolekula ili pravilnih češljastih makromolekula. ${ }^{9,10}$

\section{NOP-1.23 polimerizacija otvaranjem prstena (ring-opening polymerization)}

Polimerizacija u kojoj ciklički monomer daje monomernu jedinicu koja je aciklička ili sadržava manje prstenova nego monomer. ${ }^{9,10}$

Napomena: Ako je monomer policiklički, otvaranje jednoga prstena je dovoljno da se reakcija svrsta u polimerizaciju otvaranjem prstena.

\section{NOP-1.24 jednonitni polimer (sing/e-strand polymer)}

Polimer čije makromolekule su jednonitne makromolekule, tj. makromolekule građene od konstitucijskih jedinica koje su sa susjednim konstitucijskim jedinicama povezane preko dva atoma, po jedan na svakoj konstitucijskoj jedinici. ${ }^{1}$

Napomena: Kombinacija definicija 1.39 (jednonitna makromolekula) i 2.29 (jednonitni polimer) u lit. ${ }^{9}$

NOP-1.25 stereodeskriptor ${ }^{\mathrm{p}}$, opisnik oblika ${ }^{\mathrm{d}}$, prostorni opisnik $^{\mathrm{d}}$ (stereodescriptor)
Prefiks koji obilježava konfiguraciju (apsolutnu ili relativnu) ili konformaciju.

Napomena: Tipični primjeri su $R, S ; r, s ; P, M ; R e, S i ; E, Z$; ap, $s p ; t, g_{+}, g_{-}, \mathrm{D}, \mathrm{L}^{12}$

\section{NOP-2 IMENA HOMOPOLIMERA NA OSNOVI PODRIJETLA}

\section{NOP-2.1 Imena monomera}

\section{Pravilo 1}

Pri imenovanju polimera na osnovi podrijetla rabe se sustavna imena monomera ili zadržana uvriježena imena monomera koja sada preporučuju i IUPAC-ova pravila organskoga i anorganskoga imenovanja. ${ }^{8,13}$

Napomena 1: Postoje li alternativna imena, a u Dodatku NOP-7 nije drugačije navedeno, preporuka je rabiti preferentna IUPAC-ova imena. Tipična iznimka je uporaba imena stiren (za polistiren) umjesto preferentnoga imena etenilbenzen.

Napomena 2: Postoji također ograničen broj spornih anorganskih monomera. Za potrebe imenovanja polimera na osnovi podrijetla preporučuje se takva imena rabiti u skladu s IUPAC-ovim pravilima anorganskoga imenovanja ${ }^{13}$, a ako postoje alternativna imena, prijedlog je rabiti ona koja su bliža uporabi u organskoj kemiji.

\section{Primjeri}

1.1<smiles>C=Cc1ccccc1</smiles>

stiren

vinilbenzen

etenilbenzen (preferentno ime)

1.2<smiles>C=CC(=O)OC</smiles>

metil-prop-2-enoat (preferentno ime)

1.3<smiles>C=COC(C)=O</smiles>

vinil-acetat (preferentno ime) etenil-acetat 
1.4

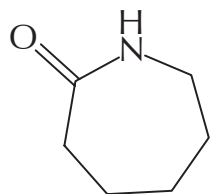

azepan-2-on (preferentno ime) heksan-6-laktam

1.5

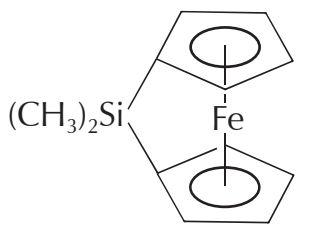

1,1'-(dimetilsilandiil)ferocen

\section{NOP-2.1.1 Prividni monomeri}

Ponekad se iz strukture polimera čini da je nastao polimerizacijom monomera koji nije upotrijebljen ili uopće ne postoji. Takav se monomer naziva prividni monomer (vidi NOP-1.1). Na primjer, poli(vinil-alkohol) se sastoji od ponavljanih jedinica koje upućuju na to da je dobiven polimerizacijom vinil-alkohola, ${ }^{14}$ nestabilnoga enolnog tautomera acetaldehida prikazanoga u primjeru 1.6. Međutim za pripravu toga polimera redovito se upotrebljava monomer vinil-acetat čijom polimerizacijom nastaje poli(vinil-acetat), a taj hidrolizom daje poli(vinil-alkohol). Sličan je, iako oprečan, slučaj poli[ $N, N^{\prime}$-(heksan-1,6-diil) adipamid], tj. nylon 6,6 koji bi se mogao smatrati produktom polimerizacije cikličkoga monomera, $N, N^{\prime}$-(heksan1,6-diil)adipamida (primjer 1.7). Još jedan takav primjer je poli(etilen-tereftalat) koji izgleda kao produkt polimerizacije cikličkoga monomera etilen-tereftalata (primjer 1.8). Također, kondenzacijski polimer poli(1,4-fenilen-sulfid) dobiven iz 1,4-diklorbenzena i natrijeva sulfida izgleda kao da je dobiven iz nepostojećega monomera 1,4-fenilen-sulfida (primjer 1.9).

\section{Primjeri}

1.6

$$
\begin{gathered}
\mathrm{CH}_{2}=\mathrm{CH}-\mathrm{OH} \\
\text { vinil-alkohol }
\end{gathered}
$$

\section{7}<smiles>O=C1CCCCCCCCCCC1</smiles>

$N, N^{\prime}$-(heksan-1,6-diil)adipamid

1,8-diazaciklotetradekan-2,7-dion
1.8

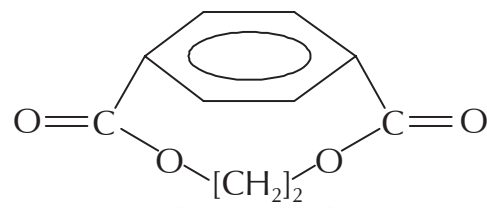

etilen-tereftalat

1.9

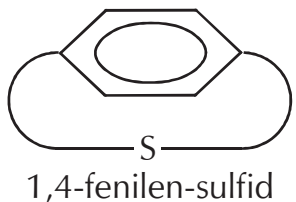

\section{NOP-2.2 Imena na osnovi podrijetla za homopolimere dobivene lančanom polimerizacijom, polimerizacijom otvaranjem prstena ili poliadicijom}

\section{Pravilo 2}

Ime na osnovi podrijetla homopolimera dobivenog lančanom polimerizacijom, polimerizacijom otvaranjem prstena ili poliadicijom tvori se dodatkom prefiksa "poli" na ime monomera. Ime monomera stavlja se unutar zagrada kada se sastoji od najmanje dvije riječi (npr. akrilna kiselina), kada sadržava najmanje jedan lokant ili stereodeskriptor (npr. but-1-en) ili kada izaziva nejasnoće.

Napomena 1: U većini slučajeva do nejasnoća dolazi ukoliko ime monomera započinje dijelom ili prefiksom čija višestrukost daje različite monomere, npr. poli(klorstiren) je polimer, a poliklorstiren je višestruko supstituirani monomer izveden iz stirena. Slično se polimer poli(oksetan) treba razlikovati od razrednoga imena polioksetan koje upućuje na četveročlane prstenove s više od jednoga kisikovog atoma.

Napomena 2: Ovisno o uvjetima polimerizacije isti monomer može dati polimere dviju ili više struktura, kao npr. buta-1,3-dien. U ovome je primjeru moguće voditi polimerizaciju tako da rastući lanac bude iniciran gotovo isključivo 1,4- ili 1,2-adicijom monomera. Oba produkta su pravilni homopolimeri, ali različitih ponavljanih jedinica. U drugačijim uvjetima polimerizacije može doći do kombinacije 1,4- i 1,2-adicija što daje nepravilni homopolimer. Shodno tome, $\mathrm{u}$ primjerima gdje određeni monomer $\mathrm{u}$ strukturu polimera unosi dvije ili više vrsta konstitucijskih jedinica, razlike u imenima produkata iskazuju se primjenom generičkoga imenovanja na osnovi podrijetla ${ }^{7}$ ili imenovanja na osnovi strukture. ${ }^{3}$

Napomena 3: Kada je ciklički monomer oligomer (dimer, trimer itd.) nekoga manjeg monomera, konstitucijska se jedinica izvodi iz manjega monomera. Na primjer, monomer 1,3,5-trioksan je ciklički trimer formaldehida, a ime polimera izvedenoga iz tog monomera je poliformaldehid, a ne politrioksan.

Napomena 4: Nije uobičajeno da se brojčane vrijednosti nekih svojstava polimera, kao što su relativna molekulska masa, stupanj polimerizacije ili u slučaju kopolimera sastav, uključuju u ime polimera. Ako je potrebno, te se 
vrijednosti mogu dodati u zagradama iza imena polimera. Tako npr. ako piše "polistiren $\left(30200 M_{\mathrm{rn}}\right)$ ", znači da je riječ o polistirenu prosječne brojčane relativne molekulske mase 30200 (vidi str. 49 u lit. ${ }^{15}$ ). Pojedinosti su opisane u odjelu 8 lit. $^{5}$

\section{Primjeri}

2.1

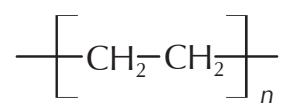

polieten

2.2<smiles>CC(CC(C)(C)C)C(C)(C)C</smiles>

2.3<smiles>CC(C)(C)CC(C#N)C(C)(C)C</smiles>

poliakrilonitril

2.4<smiles>CC(C)(C)CC(O)C(C)(C)C</smiles>

2.5<smiles>CCCCCC=CC(C)(C)C</smiles>

poli(buta-1,3-dien)

Napomena: U grafičkom prikazu polimera prednost ima dvostruka veza u položaju 1 (najmanji lokant nezasićenosti), tj. onomu koji je u skladu s imenom na osnovi strukture, ${ }^{1,16}$ poli(but-1-en-1,4-diil).

2.6<smiles>CC(C)(C)c1ccccc1</smiles>

2.7<smiles>Cc1cccc(C(C)C(C)(C)C)c1</smiles>

poli(3-metilstiren)

2.8<smiles>CCC(C)(CC)C(C)(C)C</smiles>

poli(izopropenilbenzen)

2.9<smiles>COC(=O)C(C)(C)CC(C)(C)C</smiles>

poli(metil-metakrilat)<smiles>CC(n1c2ccccc2c2ccccc21)C(F)(F)F</smiles>

2.11
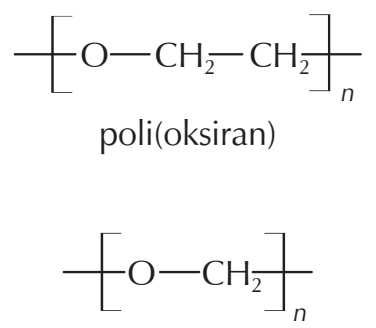

poliformaldehid 
2.14<smiles>CCCCCNC(=O)OC(C)(C)C</smiles>

poli(4-izocijanatobutan-1-ol)

Napomena: lako je ime dano u primjeru 2.14 točno, taj bi polimer mogao nastati kao zamišljeni produkt poliadicije jednoga monomera samo uz primjenu kemije zaštitnih skupina. Zbog toga je prikazani monomer prividni monomer. Poznatiji produkti reakcija poliadicije dvaju monomera razvrstani su kao izmjenični kopolimeri. Njihovo je imenovanje opisano u dijelu NOP-3.2, a prikaz dan u primjeru 3.12.

\section{NOP-2.3 Imena na osnovi podrijetla za polimere dobivene polikondenzacijom}

Postoje dvije različite vrste polikondenzacije: polikondenzacija jednoga monomera označenoga kao x-A-y i polikondenzacija dvaju monomera označenih x-A-x i y-B-y u kojima su x i y funkcijske skupine koje mogu međusobno reagirati, npr. x može biti hidroksilna, alkoksilna, amino- ili alkilamino-skupina, dok y može biti karboksilna ili karboksilatna skupina. Da bi imenovanje na osnovi podrijetla za obje vrste polikondenzacijskih polimera bila što je moguće više u skladu s dosad opisanim načelima, preporučuje se pristup prividnoga monomera.

\section{Pravilo 3}

Ime na osnovi podrijetla za homopolimerni produkt polikondenzacije tvori se stavljanjem prefiksa "poli" ispred imena prividnoga monomera. Sukladno pravilu 2 ime prividnoga monomera stavlja se između zagrada ako se sastoji od najmanje dvije riječi, ako uključuje jedan ili više prefiksa, lokanata ili deskriptora ili ako izaziva nejasnoću.

Napomena 1: U nekim primjerima polikondenzacije jednoga (bifunkcijskog) monomera označenoga kao x-A-y uobičajeno je imenovati polimer prema imenu monomera $u$ skladu s pravilom 2, tj. bolje iz imena monomera nego iz prividnoga monomera. Takvi su primjeri polialanin (primjer 2.15) i poli(mliječna kiselina) (primjer 2.16). To se preferira sve dok ime monomera slijedi IUPAC-ovo imenovanje. 8,13 $^{2}$

Napomena 2: U slučaju polikondenzacije dvaju monomera određena bi struktura polimera mogla nastati iz više različitih parova monomera. Na primjer, poli(etilen-tereftalat) može nastati reakcijom etan-1,2-diola (ili oksirana), $\mathrm{x}-\mathrm{A}-\mathrm{x}$ i tereftalne kiseline (ili njezinih derivata kao što su esteri ili halidi), y-B-y. Prema pravilu 5 (vidi dio NOP-3.2) ime toga polimera moglo bi biti poli[oksiran-alt-(tereftalna kiselina)] ili poli[(etilen-glikol)-alt-(tereftaloildiklorid)], ali i druga imena ovisno o izboru parova monomera. U praksi se susreću brojne takve polikondenzacije, za razliku od rijetkih slučajeva samokondenzacije različitih x-A-y monomera kojom nastaje isti polimer. Ćinjenica da polimer određene strukture može imati više imena na osnovi podrijetla, može izazvati zbrku i zato imena tipa poli(A-alt-B) nisu prihvatljiva osim u vrlo rijetkim primjerima kad se prividni monomer ne može imenovati.

Primjeri

2.15<smiles>CC(C(=O)NC(C)(C)C)C(C)(C)C</smiles>

polialanin

poli(2-aminopropanska kiselina)

poli(3-metilaziridin-2-on)

2.16

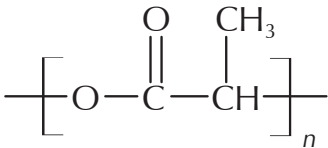

poli(mliječna kiselina)

poli(2-hidroksipropanska kiselina)

poli(3-metiloksiran-2-on)

2.17

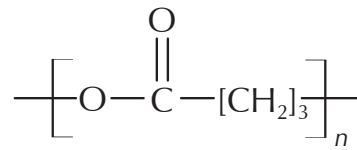

poli(oksolan-2-on)

poli(4-hidroksibutanska kiselina)

2.18

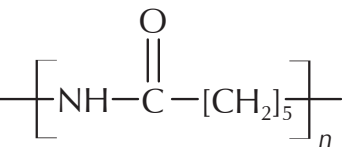

poli(azepan-2-on)

poli(6-aminoheksanska kiselina)

2.19

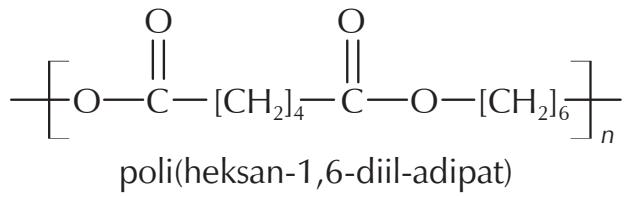

2.20

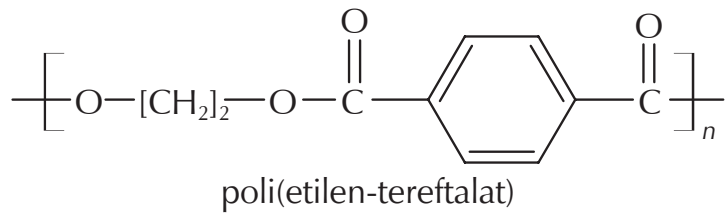

2.21<smiles>CC(C)(C)CCCCNC(C)(C)C</smiles>

poli[N,N'-(propan-1,3-diil)izoftalamid] 
2.22<smiles>CNC(=O)CCC(=O)OCCC(C)(C)C</smiles>

poli[N, N'-(heksan-1,6-diil)heksandiamid], poli[N, $N^{\prime}$-(heksan-1,6-diil)adipamid]

2.23

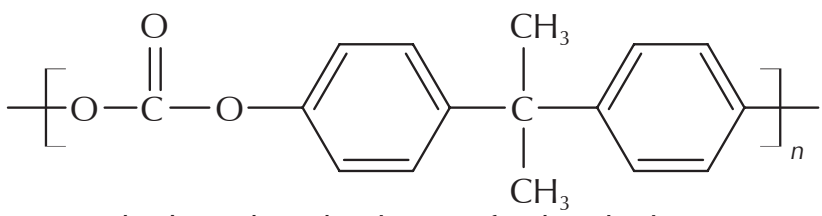

poli[(dimetilmetilen)bis(4,1-fenilen) karbonat]

\section{Literatura \\ References}

1. J. Kahovec, R. B. Fox, K. Hatada, Nomenclature for regular single-strand organic polymers. IUPAC Recommendations 2002, Pure Appl. Chem. 74 (10) (2002) 1921-1956; poglavlje 15 u lit. 15. Hrvatski prijevod: V. Jarm, Nomenklatura pravilnih jednonitnih organskih polimera. Preporuke IUPAC 2002., preporuke HDKI i HKD 2005., Kem. Ind. 55 (2) (2006) 81-104.

2. W. V. Metanomski, R. E.Bareiss, J. Kahovec, K. L. Loening, L. Shi, V. P. Shibaev, Nomenclature of regular double-strand (ladder and spiro) organic polymers. IUPAC Recommendations 1993, Pure Appl. Chem. 65 (7) (1993) 1561-1580; poglavlje 16 u lit. 15. Hrvatski prijevod: V. Jarm, Nomenklatura pravilnih dvonitnih (ljestvastih i spiro) organskih polimera. Preporuke IUPAC 1993., preporuke HDKI i HKD 1998., Kem. Ind. 47 (12) (1998) B26-B34.

3. R. B. Fox, N. M. Bikales, K. Hatada, J. Kahovec, Structure-based nomenclature for irregular single-strand organic polymers. IUPAC Recommendations 1994, Pure Appl. Chem. 66 (4) (1994) 873-889; poglavlje 17 u lit.15. Hrvatski prijevod: V. Jarm, Nomenklatura na osnovi strukture za nepravilne jednonitne organske polimere. Preporuke IUPAC 1994., preporuke HDKI i HKD 1998., Kem. Ind. 47 (12) (1998) B43-B49.

4. W. Mormann, K.-H. Hellwich, Structure-based nomenclature for cyclic organic macromolecules. IUPAC Recommendations 2008, Pure Appl. Chem. 80 (2) (2008) 201-232. Hrvatski prijevod: V. Jarm, Nomenklatura za cikličke organske makromolekule na osnovi strukture. Preporuke IUPAC 2008., preporuke HDKI i HKD 2013., Kem. Ind. 62 (9-10) (2013) 327-344.

5. W. Ring, I. Mita, A. D. Jenkins, N. M. Bikales, Source-based nomenclature for copolymers. IUPAC Recommendations 1985, Pure Appl. Chem. 57 (10) (1985) 1427-1440; poglavlje 19 u lit. 15. Hrvatski prijevod: V. Jarm, Z. Smolčić Žerdik, Nomenklatura kopolimera na osnovi njihova podrijetla. Preporuke IUPAC 1985., preporuke HDKI i HKD 1988., Kem. Ind. 37 (10) (1988) B23-B32.

6. J. Kahovec, P. Kratochvíl, A. D. Jenkins, I. Mita, I. M. Papisov, L. H. Sperling, R. F. T. Stepto, Source-based nomenclature for non-linear macromolecules and macromolecular assemblies. IUPAC Recommendations 1997, Pure Appl. Chem. 69 (12) (1997) 2511-2522; poglavlje 20 u lit 15. Hrvatski prijevod: V. Jarm, Nomenklatura na osnovi podrijetla za nelinearne makromolekule i makromolekulne nakupine. Preporuke
IUPAC 1997., preporuke HDKI i HKD 1998., Kem. Ind. 47 (12) (1998) B49-B56.

7. E. Maréchal, E. S. Wilks, Generic source-based nomenclature for polymers. IUPAC Recommendations 2001, Pure Appl. Chem. 73 (9) (2002) 1511-1519; poglavlje 21 u lit. 15. Hrvatski prijevod: V. Jarm, Generička nomenklatura polimera na osnovi njihova podrijetla. Preporuke IUPAC 2001., preporuke HDKI i HKD 2005., Kem. Ind. 55 (2) (2006) 73-80.

8. H. A. Favre, W. H. Powell, Nomenclature of Organic Chemistry (IUPAC Recommendations and Preferred Names 2013), RSC Publishing, Cambridge, UK (2013).

9. A. D. Jenkins, P. Kratochvíl, R. F. T. Stepto, U. W. Suter, Glossary of basic terms in polymer science. IUPAC Recommendations 1996, Pure Appl. Chem. 68 (12) (1996) 2287-2311; poglavlje $1 \mathrm{u}$ lit. 15. Hrvatski prijevod: V. Jarm, Glosar osnovnih pojmova u znanosti o polimerima. Preporuke IUPAC 1996., preporuke HDKI i HKD 1998., Kem. Ind. 47 (12) (1998) B5-B19.

10. IUPAC, Compendium of Chemical Terminology, $2^{\text {nd }} \mathrm{Ed}$. (the "Gold Book"). Compiled by A. D. McNaught and A. Wilkinson. Blackwell Scientific Publications, Oxford (1997). $\mathrm{XML}$ on-line corrected version: http://goldbook.iupac.org (2006-) created by M. Nic, J. Jirat, B. Kosata; updates compiled by A. D. Jenkins. ISBN0-9678550-9-8, doi: https://doi. org/10.1351/goldbook.

11. S. Penczek, G. Moad, Glossary of terms related to kinetics, thermodynamics and mechanisms of polymerization IUPAC Recommendations 2008, Pure Appl. Chem.80 (10) (2008) 2163-2193. Hrvatski prijevod: E. Vidović, Glosar pojmova vezan uz kinetiku, termodinamiku i mehanizme polimerizacije. Preporuke IUPAC 2008., preporuke HDKI i HKD 2012., Kem. Ind. 61 (4) (2012) 215-236.

12. G. P. Moss, Basic terminology in stereochemistry. IUPAC Recommendations 1996, Pure Appl. Chem. 68 (12 ) (1996) 2193-2222. Hrvatski prijevod: M. Žinić, Osnovno stereokemijsko nazivlje, Preporuke IUPAC 1996., preporuke HDKI i HKD 2001., HDKI / Kemija u industriji, Zagreb, 2001.

13. IUPAC. Nomenclature of Inorganic Chemistry, IUPAC Recommendations 2005 (the "Red Book") prepared for publication by N. G. Connelly, T. Danhus, R. M. Hartshorn and A. T. Hutton, RSC Publishing, Cambridge, UK (2005).

14. B. M. Novak, A. K. Cederstav, The polymerization of free enols with electron-deficient comonomers, J. Macromol. Sci. - Part A, A34, (1997) 1815-1825.

15. IUPAC. Compendium of Polymer Terminology and Nomenclature, IUPAC Recommendations 2008 (the "Purple Book"). Prepared for publication by R. G. Jones, J. Kahovec, R. Stepto, E. S. Wilks, M. Hess, T. Kitayama, W. V. Metanomski, with advice from A. Jenkins and P. Kratochvíl, RSC Publishing, Cambridge, UK (2009).

16. W. Mormann, K.-H. Hellwich, J. Chen, E. S. Wilks, Preferred names of constitutional units for use in structure-based names of polymers. IUPAC Recommendations 2017, Pure Appl. Chem. 89 (11) (2017) 1695-1736.

17. R. E. Bariess, J. Kahovec, P. Kratochvíl, Graphic representation (chemical formulae) of macromolecules. IUPAC Recommendations 1994, Pure Appl. Chem. 66 (12) (1994) 2469-2482; poglavlje 18 u lit. 15. Hrvatski prijevod: V. Jarm, Grafičko prikazivanje (kemijske formule) makromolekula. Preporuke IUPAC 1994., preporuke HDKI i HKD 1998., Kem. Ind. 47 (12) (1998) B34-B42.

18. R. S. Jones, T. Kitayama, E. S. Wilks, and others, Nomenclature and graphic representation of chemically modified polymers. IUPAC Recommendations 2014, Pure Appl. Chem. 87 (3) (2015) 307-319. Hrvatski prijevod: V. Jarm, Nomenklatura i grafičko prikazivanje kemijski modificiranih polime- 
ra. Preporuke IUPAC 2014., preporuke HDKI i HKD 2016. Kem. Ind. 65 (9-10) (2016) 483-494.

19. M. Barón, K.-H. Hellwich, M. Hess, K. Horie, A. D. Jenkins, R. G. Jones, J. Kahovec, P. Kratochvíl, W.V. Metanomski, W. Mormann, R. F. T. Stepto, J. Vohlídal, E. S. Wilks, Glossary of class names of polymers based on chemical structure and molecular architecture. IUPAC Recommendations 2009, Pure Appl. Chem. 81 (6) (2009) 1131-1186. Hrvatski prijevod: V. Jarm, Glosar razrednih imena polimera na osnovi kemijske strukture i molekulne arhitekture. Preporuke IUPAC 2009., preporuke HDKI i HKD 2012., Kem. Ind. 61 (3) (2012) 145-176.

\title{
SUMMARY
}

\section{Source-based Nomenclature for Single-strand Homopolymers and Copolymers (Part I) (IUPAC Recommendations 2016)}

\author{
Translated by Vida Jarm
}

IUPAC recommendations on source-based nomenclature for single-strand polymers have so far addressed its application mainly to copolymers, non-linear polymers and polymer assemblies, and within generic source-based nomenclature of polymers. In this document, rules are formulated for devising a satisfactory source-based name for a polymer, whether homopolymer or copolymer, which are as clear and rigorous as possible. Thus, the source-based system for naming polymers is presented in a totality that serves as a user-friendly alternative to the structure-based system of polymer nomenclature. In addition, because of their widespread and established use, recommendations for the use of traditional names of polymers are also elaborated.

\section{Keywords}

Apparent monomer, copolymer, end-groups, homopolymer, IUPAC, IUPAC nomenclature, monomer, nomenclature, polymers, polymer nomenclature, source-based names, traditional names

Rudolfa Bićanića

Nomenclature note 10000 Zagreb

Croatia 